\title{
ANÁlise COMPARATIVA DA CICATRIZAÇÃO DA PELE COM O USO INTRAPERITONEAL DE EXTRATO AQUOSO DE Orbignya phalerata (BABAÇU). ESTUDO CONTROLADO EM RATOS ${ }^{1}$
}

\author{
Healing process in cutaneous surgical wounds in rats under the influence of Orbignya phalerata \\ aqueous extract
}

\author{
Nelson Lúcio Parada Martins ${ }^{2}$, Osvaldo Malafaia ${ }^{4}$, Jurandir Marcondes Ribas-Filho ${ }^{4}$, Marcel Heibel ${ }^{5}$, Raimundo \\ Nonato Baldez ${ }^{3}$, Paulo Roberto Leitão de Vasconcelos ${ }^{4}$, Hamilton Moreira ${ }^{4}$, Marcelo Mazza ${ }^{4}$, Paulo Afonso Nunes \\ Nassif $^{4}$, Tatiana Zacharow Wallbach ${ }^{5}$
}

1. Trabalho realizado no laboratório de pesquisas do centro de Ciências Biológicas e da Saúde da Universidade Federal do Maranhão

2. Professor do Departamento de Cirurgia da Universidade Federal do Maranhão

3. Médico do Hospital da Universidade Federal do Maranhão

4. Professor Doutor em Cirurgia

5. Aluno de Pós-Graduação - Mestrado

\begin{abstract}
RESUMO
Introdução: A cicatrização das feridas é processo altamente complexo com várias fases. Inúmeras substâncias têm sido usadas desde os tempos remotos para estimulá-la. Entre elas, o extrato da Orbignya phalerata com possível ação estimulante da cicatrização. Objetivo: verificar a ação cicatrizante da Orbignya phalerata na cicatrização das feridas cirúrgicas da pele através de análise comparativa das alterações histológicas e morfológicas. Métodos: Foram utilizados 60 ratos, da linhagem Wistar, adultos e machos. Para o experimento, eles foram distribuídos de forma aleatória em dois grupos de 30 cada e usada a substância Orbignya phalerata intraperitoneal na dose de $50 \mathrm{mg} / \mathrm{Kg}$, no primeiro dia da operação em um dos grupos. O procedimento experimental constituiu-se em incisão cutânea circular de dois centímetros de diâmetro com punch metálico. No grupo controle não foi usada a substância. Os ratos foram mortos nos $7^{\circ}, 14^{\circ}, 21^{\circ}$ dias do pós-operatório. Realizou-se a análise macroscópica com lupa e paquímetro, para avaliação da evolução do aspecto da lesão cicatricial e morfométrica da ferida feita por análise histológica; as lâminas foram coradas com Hematoxilina-Eosina (HE) e tricrômio de Masson e observaram-se a proliferação vascular, células mononucleares, células polimorfonucleares, proliferação fibroblástica, fibras colágenas e reepitelização. Resultados: Mostraram na macroscopia dos animais do grupo experimento de sete dias que um apresentou pequena quantidade de secreção sem outras alterações dignas de nota; nos animais de 14 dias identificou-se todos com ferida de bom aspecto; nos de 21 dias, foi observada a presença de cicatrização completa em todos os animais. Quanto à análise histológica, houve diferença significativa entre os grupos nas variáveis monocelulares e fibras colágenas em todos os dias, e no $7^{\circ}$ dia foi observada diferença significativa na proliferação fibroblástica e reepitelização. Conclusão: observou-se efeito favorável do extrato aquoso do mesocarpo do babaçu em nível microscópico do processo de cicatrização, nas variáveis mononucleares e fibras colágenas, em todos os dias e entre os grupos.
\end{abstract}

Descritores: Cicatrização de Feridas. Fitoterapia. Orbignya phalerata. Fisiologia da Pele.

\begin{abstract}
Introduction: The wounds healing is a highly complex process with many phases. Countless substances have been used since the remote times with the purpose a simulating the process. Among them the Orbignya phalerata extract was considered as having a stimulating action. Purpose: The aim of this study is to verify the healing action of the Orbignya phalerata in the healing of skin surgical wounds by a comparative analysis of the alterations obtained in histological and morphologic aspects. Methods: Sixty male adult Wistar rats were used. They were distributed in a randomly in two groups of 30 each and, in one group, Orbignya phalerata extrac was used intraperitoneally in a dose of $50 \mathrm{mg} / \mathrm{Kg}$ in the first day of surgery. The experimental procedure consisted in a circular incision of two centimeters of diameter with metallic punch. In the control group the substance was not used. The rats were killed in the 7th, 14th, 21 st days of the post-operative period and submitted to macro and microscopic analysis. The macroscopic one was made with magnifying glass and paquimeter. For the histological analysis, the sheets were processed with Hematoxilina-Eosina (HE) and tricromic of Masson and slides the vascular proliferation, monucleares cells, polimorfonuclear cells, fibroblastic proliferation, colagens fibers and reepitelization were assined. Results: In the macroscopic view the experimental group of seven days had only one animal with small amount of secretion. In the animals of 14 days all of them had good aspect. The ones of 21 days, complete healing
\end{abstract}


was observed in all animals. In the histological analysis, there was no significant difference among groups, except for the 7th day with significant difference in the fibroblastic proliferation and reepitelization favoring the experimental group. Conclusion: A favorable effect of the aqueous extract of babassu mesocarp was observed in a microscope analysis in the healing process of cutaneous surgical wounds in rats.

Key Words: Wound Healing. Phytotherapy. Orbignya phalerata. Physiology, Skin.

\section{Introdução}

A cicatrização das feridas é processo altamente complexo. Nele existe uma seqüência de estágios interdependentes e sobrepostos descritos como inflamação (fase exudativa), reconstrução (fase proliferativa), epitelização (fase regenerativa) e maturação.

Há diversos fatores que podem afetar positiva ou negativamente o processo de cicatrização, tais como: a) o ambiente mais ou menos contaminado no qual ocorre a ferida; b) infecção sistêmica concomitante, onde se retarda a cicatrização devido a que a ferida disputa os mesmos glóbulos brancos e nutrientes, com a infecção; c) o estado nutricional que, quando deficitário, diminui as resistências orgânicas naturais à infecção; d) doenças sistêmicas associadas, como diabetes e obesidade mórbida, que por hiperglicemia (diabetes) afeta o mecanismo de defesa do corpo, prejudicando a resposta dos glóbulos brancos em geral e dos neutrófilos em particular; e) riscos especiais, como radioquiomioterapia, uso de AINES e drogas imunossupressoras ${ }^{1,2}$.

Os principais fatores que podem favorecem a cicatrização são: a) programas de controle de infecções; b) combate ao estresse, devido a sua interferência malévola no equilíbrio hormonal orgânico; c) uso de substâncias farmacológicas que comprovadamente apresentem favorecimento do processo cicatricial.

O Brasil é depositário de enorme flora riquíssima em matéria prima que tem despertado o interesse de pesquisadores de várias universidades e instituições dedicadas a fitoterapia. A região amazônica é considerada fonte inesgotável de potencialidades terapêuticas com o uso de plantas medicinais.

A Universidade Federal do Maranhão (UFMA) tem programa de valorização das plantas medicinais através de coleta do material botânico na pré-amazônia maranhense. Todo o material lá existente é herborizado e registrado no Herbário da Universidade, inventariado, registrado e pesquisado. Com isto, há o incentivo da implantação de hortas medicinais comunitárias e farmácias verdes, oferecendo medicina alternativa de elevado alcance social, contudo de baixo nível de comprovação científica.

Entre as várias plantas estudadas se inclui a Orbignya phalerata ou babaçu (catalogada com o número 1136 do Herbário Ático Seabra - UFMA). O mesocarpo do babaçu é usado em solução aquosa em várias doenças segundo a crença popular, inclusive como antiinflamatório e cicatrizante $^{3}$. Desde 1950 tem sido realizado elevado número de pesquisas para sua utilização como medicamento, contudo carecendo até agora de demonstração fitoquímica de quais elementos possuem o efeito favorecedor da cicatrização. Não há ainda fracionamento suficiente para lá se chegar.

Foi observado que o tratamento com o babaçu induziu a ativação de macrófagos levando ao aumento da produção de óxido nítrico e a liberação da histamina que estimula a atividade fagocítica. Este fato, favorece a destruição dos tecidos no local de formação dos complexos imunes ${ }^{4}$.

A ativação dos macrófagos durante a fase inicial da cicatrização é parcialmente propiciada pelo óxido nítrico, que age estimulando as propriedades antimicrobianas naturais. Alguns estudos comprovam que a inibição da síntese do óxido nítrico em camundongos afeta a cicatrização das feridas, o que sugere existir papel adicional ao antimicrobiano durante a cicatrização ${ }^{5}$.

Em estudos intraperitoneais e em animais pré-tratados com babaçu, parece que a produção de óxido nítrico é realizada a partir de nitritos nas células peritoneais ${ }^{6}$.

$\mathrm{O}$ extrato clorofórmico do pó do mesocarpo do babaçu já foi utilizado em vários ensaios farmacológicos, muitos deles em modelos experimentais de inflamação. Provou-se ter quase a mesma intensidade da ação antiinflamatória da fenilbultazona na dose de $100 \mathrm{mg} / \mathrm{kg}$ intraperitoneal com metade dela, ou seja, $50 \mathrm{mg} / \mathrm{kg}$ deste extrato mostram atividade antiinflamatória comparável ${ }^{7}$.

Assim, este estudo visa substanciar dados que auxiliem a comprovar se existe ação cicatrizante na Orbignya phalerata com seu uso em feridas cirúrgicas da pele, através de análise comparada das alterações macroscópicas e histológicas que proporciona.

\section{Métodos}

Este estudo foi realizado no Laboratório de Bioquímica do Departamento de Fisiologia e Farmacologia do Centro de Ciências Biológicas e da Saúde da Universidade Federal do Maranhão (UFMA). Foram obedecidos os princípios éticos em experimentação animal, preconizado pelo Colégio Brasileiro de Experimentação Animal (COBEA), respeitada a legislação brasileira de animais de experimentação (Lei Federal $n^{\circ} 6.638$-1997) e o projeto da pesquisa foi submetido à apreciação e aprovação do Comitê de Ética em Pesquisa - CEP do Hospital Universitário Presidente Dutra - HUPD - UFMA.

\section{Amostra e identificação dos animais.}

Foram utilizados 60 ratos (Rattus novergicus albinus, Rodentia mamalia), da linhagem Wistar, adultos, machos, com idade média de 45 dias pesando entre 129 e 234 gramas, adquiridos no Biotério Central da Universidade de Campinas - São Paulo (UNICAMP), e transferidos para o Laboratório de Bioquímica do Departamento de Fisiologia do Centro de Ciências Biológicas e da Saúde da Universidade Federal do Maranhão. Permaneceram em gaiolas plásticas padrão, cinco animais em cada, mantidos em temperatura e umidade 
naturais do ambiente, com livre acesso a água e ração de origem industrial (Purina ${ }^{\circledR}$ Labina), em ciclo circadiano, forradas com serragem de pinho. Institui-se o período de aclimatação por sete dias. Os animais foram distribuídos de forma aleatória em dois grupos de 30, sendo um como Grupo Controle (GC) e outro como Grupo de Experimentação (GE). Cada grupo foi ainda subdividido em três outros subgrupos conforme o período de sacrifício: sete, 14 ou 21 dias. Foram identificados, marcados com ácido pícrico e pesados em balança eletrônica digital.

\section{Preparo do extrato aquoso da Orbignya phalerata}

O mesocarpo da Orbignya phalerata foi obtido a partir do coco maduro. A coleta foi feita quando estavam caindo naturalmente dos cachos. Para retirada do mesocarpo, utilizou-se um artefato de madeira batendo manualmente na parte superior até ruptura das cascas e em seguida, com o auxilio de uma espátula, separou-se o mesocarpo. O material obtido foi espalhado sobre uma bancada durante três dias para secar e a seguir colocado em estufa de secagem em temperatura de $45-50^{\circ} \mathrm{C}$ durante 24 horas para retirada total da umidade. Foi então submetido ao processo de moagem em moinho elétrico do Laboratório do Pavilhão Tecnológico da Universidade Federal do Maranhão - UFMA, onde se obteve um pó em forma de farinha. Para a preparação do extrato aquoso, o pó foi diluído em solução salina para fazer concentração de $50 \mathrm{mg} / \mathrm{kg}$

\section{Etapa experimental}

Os animais tiveram a ração suspensa por quatro horas antes dos procedimentos cirúrgicos, porém permaneceram com acesso à água ad libitum.

Os procedimentos anestésicos foram realizados em todos os animais da mesma forma, colocando-os em campânula de plástico fechada com algodão hidrófilo umedecido com éter etílico8, até atingir o nível de anestesia, com nenhum movimento da cabeça, extremidades ou tronco, desaparecimento dos reflexos palpebrais e ritmo respiratório constante. Cada animal foi colocado sobre prancha cirúrgica em decúbito ventral imobilizado por tensores elásticos, com manutenção anestésica feita por inalação intermitente de éter sulfúrico; para tanto, foi usada máscara artesanal confeccionada com seringa de $60 \mathrm{ml}$ sem êmbolo, contendo algodão embebido em éter sulfúrico no seu interior, ficando o segmento cefálico do animal parcialmente no interior da seringa

Após anestesiados, todos submeteram-se ao mesmo procedimento operatório que consistiu inicialmente na epilação por tração manual dos pêlos do dorso com extensão de $6 \mathrm{~cm}$ no comprimento e $4 \mathrm{~cm}$ na largura, caudalmente a uma linha imaginária que passasse na borda inferior das orelhas.

A seguir foi realizada incisão circular de $2 \mathrm{~cm}$ de diâmetro no centro da área epilada, com um punch metálico cortante (Figura 1). Com tesoura, aprofundou-se a incisão até a fáscia. A hemostasia foi feita por compressão digital com gases e assim terminou o procedimento.

Nenhum animal recebeu curativo na ferida cirúrgica. Os do grupo $\mathrm{GE}$, receberam neste momento $1 \mathrm{~mL}$ do extrato

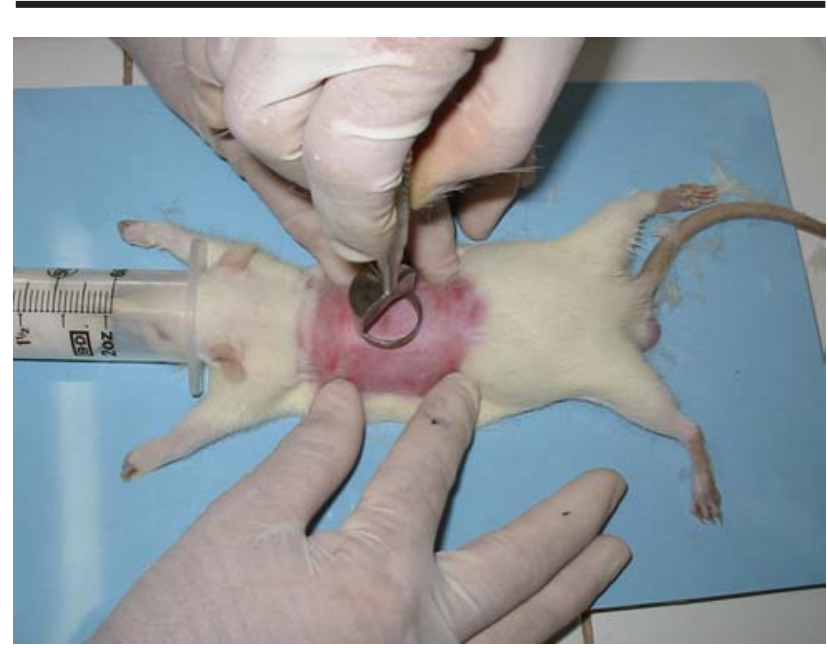

FIGURA 1 - Rato depilado para incisão dorsal com o punch

aquoso por via intraperitoneal em dose única de $50 \mathrm{mg} / \mathrm{kg}$ no $1^{\mathrm{o}}$ dia antes da operação (Figura 2). Foram sacrificados no $7^{\circ}, 14^{\circ}$ e $21^{\circ}$ dias do pós-operatório.

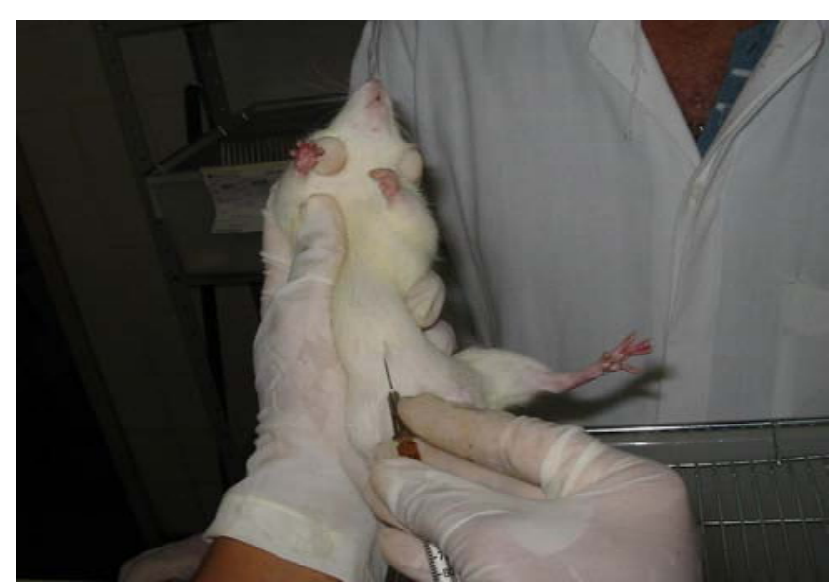

FIGURA 2 - Momento da injeção intraperitoneal na face anterior do abdomen. Observou-se a introdução da agulha na região média e anterior do abdome

No final do procedimento, os animais foram colocados em gaiolas gerais para observação da recuperação anestésica, com a normalização da freqüência respiratória e início da movimentação ativa e busca de alimentação e água.

Posteriormente, foram recolocados nas suas respectivas gaiolas recebendo alimentação no pós-operatório imediato. Eles foram identificados com o dia do procedimento operatório e o tipo do tratamento que receberam (aplicação ou não de $50 \mathrm{mg} / \mathrm{kg}$ dose única intraperitoneal).

A morte foi realizada com prévia pesagem de todos os animais e colocação um a um em campânula de vidro, contendo dose letal de éter sulfúrico, até que ocorresse o óbito. 


\section{Avaliação macroscópica}

Após a morte, os animais foram fixados à prancha cirúrgica, do mesmo modo que no ato operatório, e tiveram as feridas examinadas com auxílio de lupa com 2,5 vezes de aumento para verificação de crostas, secreções, cicatrizes hipertróficas e o tamanho da ferida residual no maior e menor eixo, medidas com paquímetro digital. Nesse tempo, os achados foram anotados em ficha protocolo e foi feito o registro fotográfico com câmera digital com zoom de 1,3 de aproximação fixada em tripé. Com esses valores, calculou-se a área da ferida, utilizando-se a planigrafia digital, transferindo a imagem para o software Auto Cad 14, após delimitar a periferia da lesão, demarcados os pontos pelo método poliline e realizado o cálculo da área. A medida do maior diâmetro foi determinada usando o paquímetro digital transformando-a em medida digital (Figuras 3 e 4).

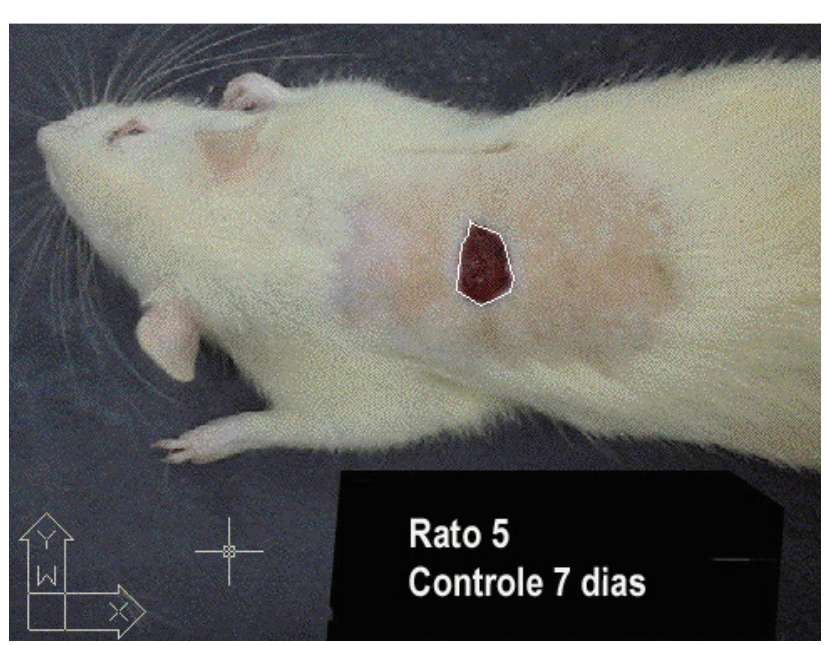

FIGURA 3 - Exemplo de delimitação da área da lesão por planimetria digital pelo método poliline.

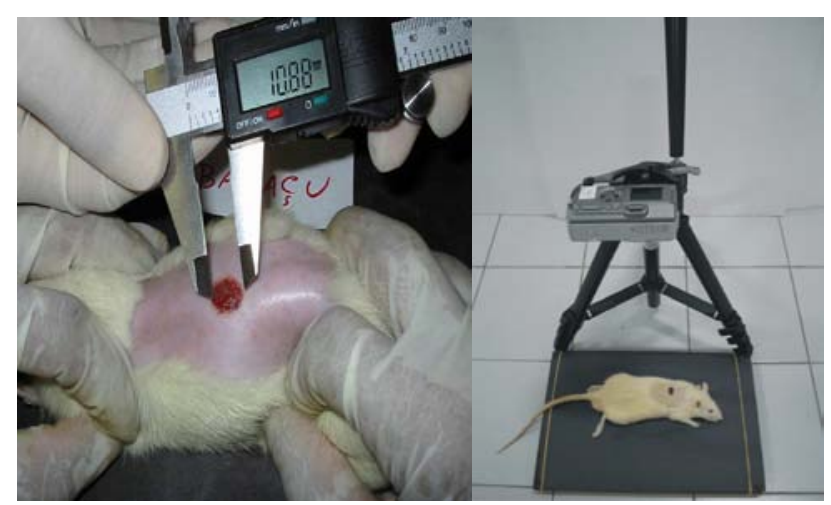

FIGURA 4 - Paquímetro e tripé para medir e fotografar lesão. Observou-se a medição dos eixos da lesão e máquina digital com distância definida da prancha cirúrgica
Após este procedimento, a área da pesquisa foi retirada com margem de $1 \mathrm{~cm}$ de pele em torno da lesão com profundidade até a fáscia. Identificou-se cada peça isoladamente que, a seguir, foi colocada em solução de formol a 10\% em recipiente de plástico, depois de fixadas por alfinetes e foram encaminhadas para avaliação histológica.

\section{Avaliação microscópica}

Os cortes histológicos foram corados com hematoxilinaeosina (H.E.) e tricômico de Masson este último usado para coloração específica de colágeno. De cada ferida foram obtidas seis lâminas que foram avaliadas quanto a presença de vasos sanguíneos na área de cicatrização, bem como, reepitelização, proliferação de colágeno, presença de fibroblastos, leucócitos e mono e polimorfonucleares.

A análise microscópica foi realizada anotando-se os achados de modo qualitativo e quantitativo. A avaliação quantitativa foi realizada com base em análise comparativa entre os três períodos de observação (7, 14 e 21 dias).

\section{Análise estatística}

Foi feita considerando-se dois tipos de hipótese: a de nulidade que, visava testar a igualdade entre o GC e GE e a alternativa, que, ao contrário da primeira, tentava verificar a diferença entre os dois grupos.

Os dados estatísticos foram analisados utilizando-se o programa Statistica for Windows 5.1. As variáveis, peso inicial e final foram analisadas pelo teste $t$ de Student. A análise conjunta dos efeitos do dia $(7,14$ e 21) e do grupo (controle e experimento) de variável numérica (área cirúrgica) foi feita pelo teste de ANOVA, isto é, análise de variância com dois fatores, dia e grupo com interação entre eles. As variáveis da avaliação histológica foram analisadas pelo teste não paramétrico de Mann-Whitney. O nível de significância p, utilizado para se rejeitar a hipótese de nulidade foi de $5 \%$ $(\mathrm{p}<0,05)$.

\section{Resultados}

\section{Avaliação macroscópica}

Durante a aplicação intraperitoneal da solução aquosa de babaçu não houve intercorrência digna de nota. O punch metálico cortante permitiu que se realizasse a excisão da peça em toda sua espessura em todos os animais e a hemostasia por compressão digital com gazes umedecidas com soro fisiológico foi eficiente evitando sangramento expressivo.

Os animais do GE e do GC apresentaram as feridas limpas sem alterações evidentes e não ocorreu nenhum óbito, ao contrário, estavam todos em bom estado de higidez. Não foram observados sinais de auto-agressão ou de mordedura de outros animais sobre a área cruenta. A manipulação dos animais foi a mesma em ambos os grupos, e não produziu estresse não interferisse no processo de cicatrização.

Apenas dois animais, um no GE e um no GC, apresentaram secreção purulenta, macroscopicamente identificada no $7^{\circ}$ dia. 
Na macroscopia dos animais do GE de sete dias, nove apresentaram crostas de bom aspecto sem secreção, e um com pequena quantidade de secreção. Nos animais de 14 dias, identificaram-se todos com crosta de bom aspecto e abaixo delas tecido de cicatrização. Nos de 21, foi observado presença de crosta seca e cicatrização completa em todos os 10 animais

Em relação ao GC de sete dias, oito animais apresentaram crosta de bom aspecto, um com secreção purulenta e outro com crosta parcial. Nove do GC de 14 dias apresentaram crosta com bom aspecto e cicatrização abaixo delas e um não cicatrizado. Os 10 animais que pertenceram ao grupo de 21 dias, todos tiveram crosta seca descamante e bom aspecto cicatricial ao final do período.

Observou-se pela análise macroscópica que o GE de sete dias apresentou eixos menores; alguns de 14 dias também tiveram a ferida menor e os de 21 estavam totalmente cicatrizados (Figura 5).
Pode-se observar na Tabela 1 a análise da variância da planigrafia da área cirúrgica que mostra dois efeitos significativos, o de dias (D) e o da interação dia versus grupos (D x G). Já o efeito do grupo $(\mathrm{G})$, não foi significativo.

TABELA 1 - Variância da planigrafia da área cirúrgica

\begin{tabular}{lcccc}
\hline FV & GL & QM & F & p \\
\hline Dias (D) & 2 & 9,9893 & 113,3351 & $* 0,0000$ \\
Grupo (G) & 1 & 0,1096 & 1,2437 & 0,2697 \\
D X G & 2 & 0,2801 & 3,1774 & $* 0,0496$ \\
Residuo & 54 & 0,0881 & & \\
\hline
\end{tabular}

Pode-se observar também na Figura 6 as médias relacionadas à área cirúrgica. Nota-se que a do dia sete foi muito alta e difere das outras duas. Já as dos dias 14 e 21 estão mais próximas entre si, por isso houve efeito significativo
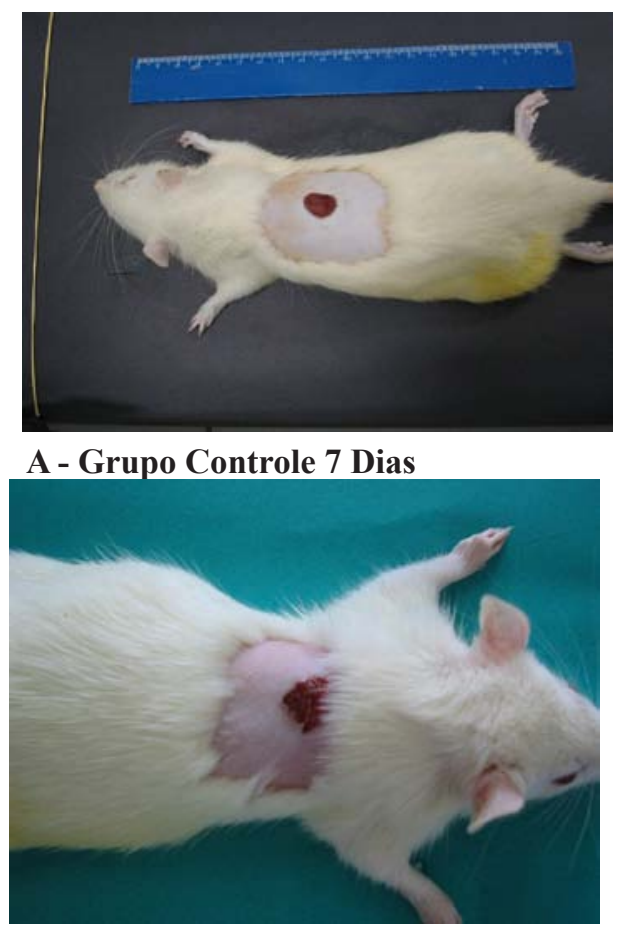

C - Grupo Controle 14 Dias

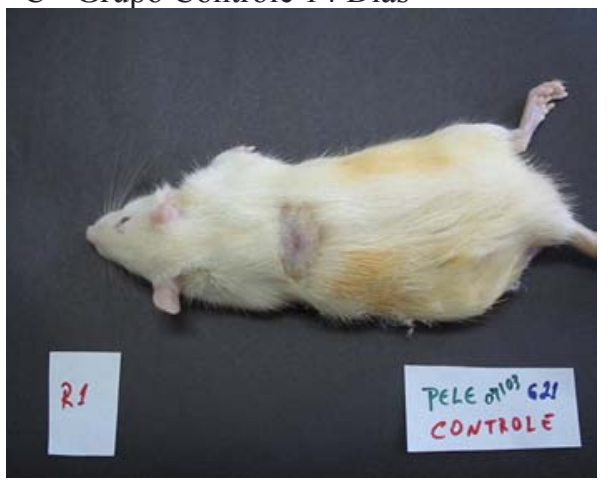

E - Grupo Controle 21 Dias

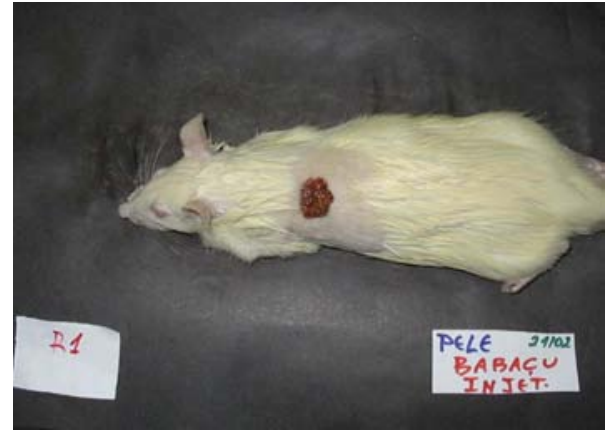

B - Grupo Experimento 7 Dias

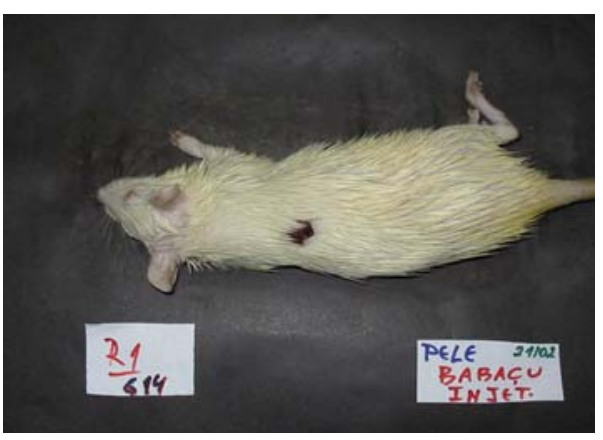

D - Grupo Experimento 14 Dias

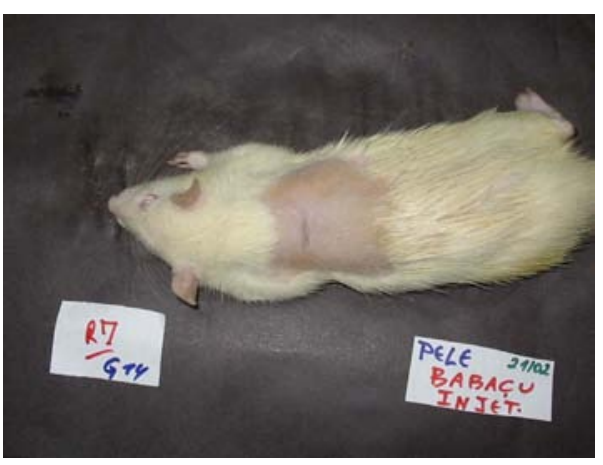

F - Grupo Experimento 21 Dias

FIGURA 5 - Evolução da cicatrização nos grupos de sete, 14 e 21 dias 
de média. Nota-se também que houve efeito de dia no processo de cicatrização; quanto maior o tempo menor ficou a área cirúrgica.

Ao analisar a Tabela 2 nota-se que a média do GC foi de $0,52 \mathrm{~cm}^{2}$ e a do GE de 0,43 . Ao fazer o teste de Tuckey, confirma-se que realmente não houve diferença significativa.

As Figura 5 e 6 dão dá noção desta diferença entre os grupos que, mesmo não demonstrando um efeito significa- tivo, realça tendência de redução da área cirúrgica a favor

TABELA 2 - Teste de Tuckey em grupos

\begin{tabular}{cc}
\hline Grupo & Área \\
\hline Controle & $* 0,5226$ \\
Experimento & $* 0,4372$ \\
\hline
\end{tabular}

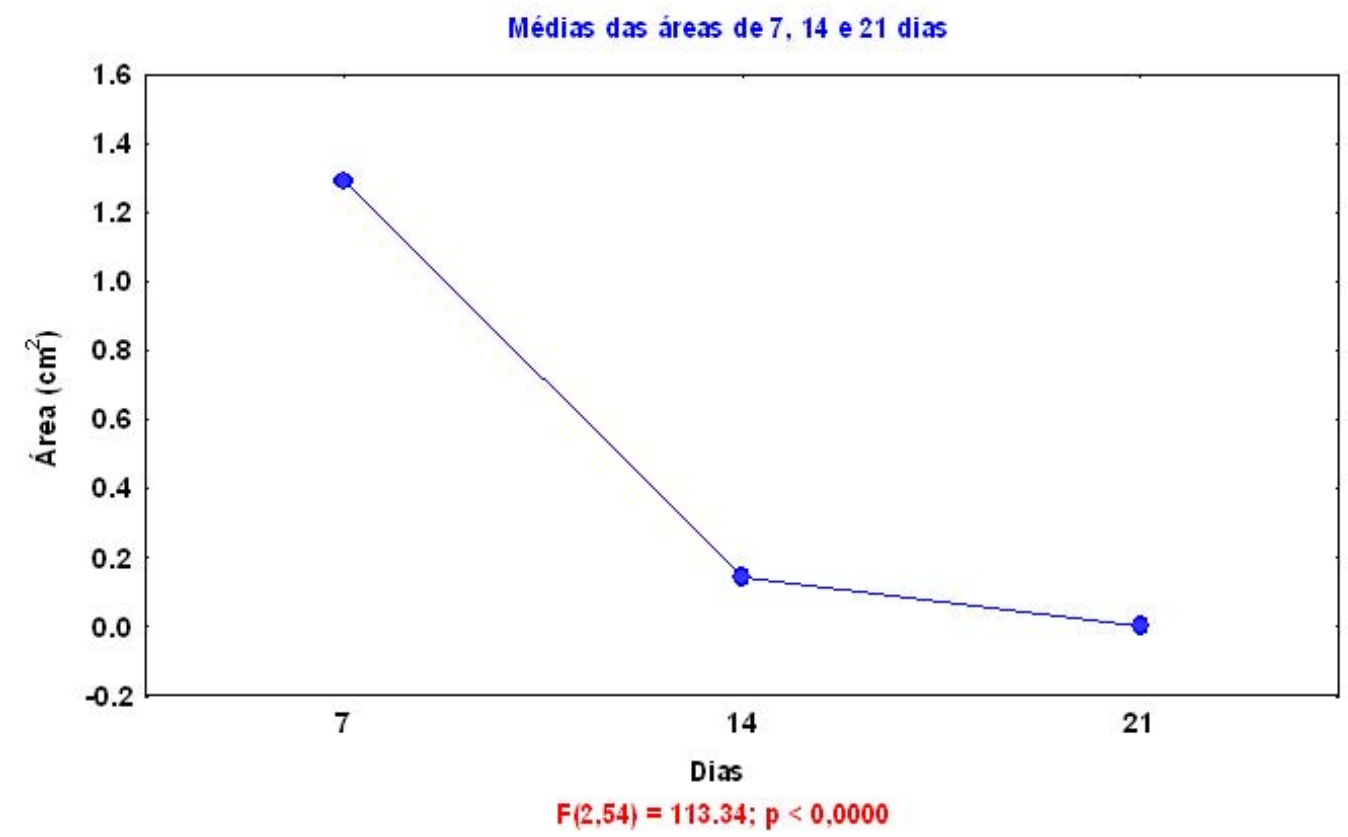

FIGURA 6 - Medidas das áreas cirúrgicas de sete, 14 e 21 dias. Legenda: $F=$ teste para comparar as variâncias e p= teste para comparar o nível de significância

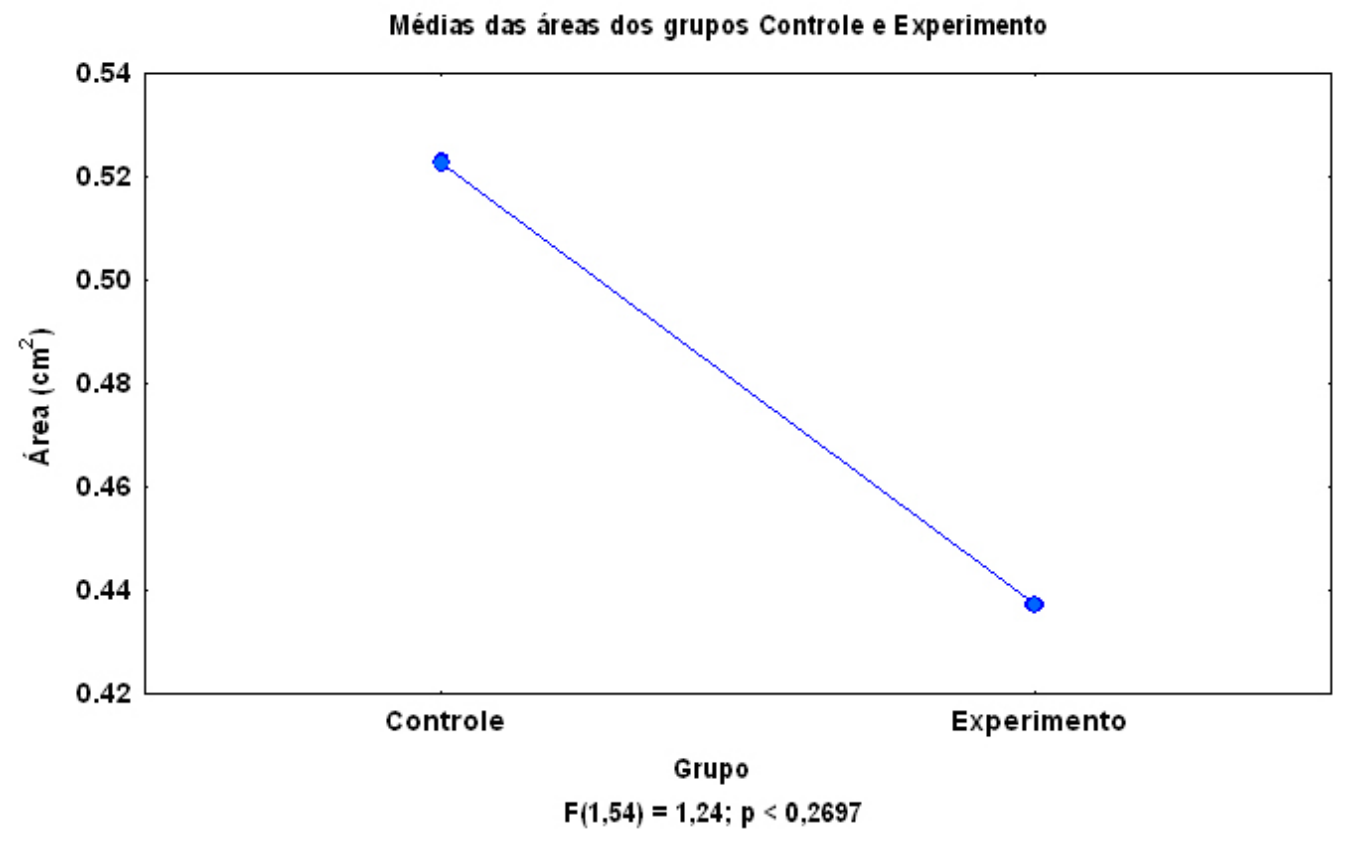

FIGURA 7 - Medidas das áreas cirúrgicas dos grupos controle e experimento. Legenda: $\mathrm{F}=$ teste para comparar as variâncias e p= teste para comparar o nível de significância 
do GE.

Já nas Figuras 8 e 9 da interação DxG pode-se observar que os grupos não se comportaram igualmente de forma paralela em relação aos dias, havendo um cruzamento do efeito do GE. No $7^{\circ}$ dia a área cirúrgica do GE foi significativamente menor do que a do GC. Já no $14^{\circ}$, a média de cicatrização do GE foi maior que a do GC, entretanto essa diferença foi pequena, e no $21^{\circ}$ dia elas praticamente são iguais.

\section{Avaliação microscópica}

No $7^{\circ}$ dia, pôde-se observar que quatro das seis variáveis que foram quantificadas deram efeito significativo quando comparado GC com o GE, são elas: mononucleares, polifibroblastos, fibras colágenas e reeptelização (Tabela 3).
TABELA 3 - Medianas dos grupos GC e GE das variáveis histológicas. Teste de mann-whitney sete dias

\begin{tabular}{ccccc}
\hline & Controle Experimento & $\mathbf{U}$ & $\mathbf{p}$ \\
\hline $\begin{array}{c}\text { Proliferação } \\
\text { vascular }\end{array}$ & 3 & 3 & 3 & 0,450 \\
Mononucleares & 2 & 2 & 2 & $* 0,049$ \\
Polimorfos & 3 & 3 & 3 & 0,791 \\
Proliferação & 1 & 2 & 1,5 & $* 0,002$ \\
fibroblástica & & & & \\
Fibras colágenas & 0,5 & 1 & 0,75 & $* 0,038$ \\
Reepitelização & 0 & 1 & 0,5 & $* 0,001$ \\
\hline
\end{tabular}

Nota: A tabela mostra que a proliferação fibroblastica, fibras colágenas e reepitelização foram maiores no grupo experimento. Em mononucleares, apesar da mediana ser igual a sua distribuição, foi diferente nos dois grupos.

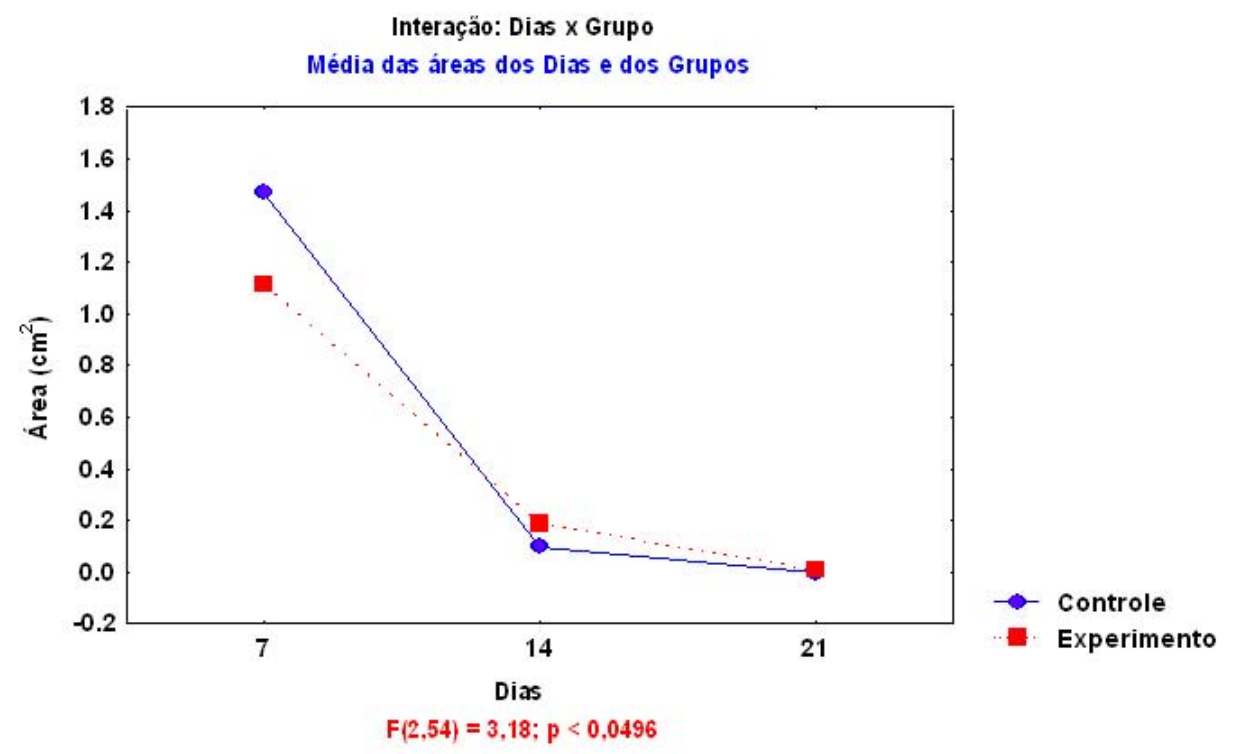

FIGURA 8 - Médias das áreas dos dias e dos grupos. Legenda: F= teste para comparar as variâncias e p= nível de significância

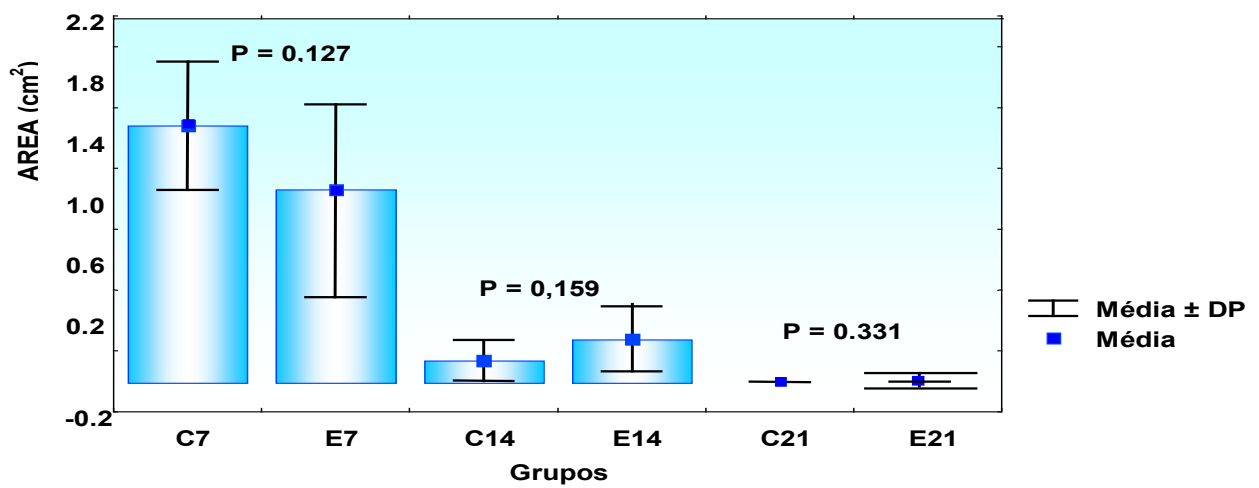

FIGURA 9 - Medidas das áreas cirúrgicas de sete, 14 e 21 dias 
Em mononucleares, a classificação maior foi do GC; já nas outras três características, o GE sempre teve valores superiores; já polimorfonucleares e proliferação vascular não apresentaram diferença significativa.

No $14^{\circ}$ dia, houve redução do número de variáveis que tiveram diferença significativa; só continuaram mantendo nas

TABELA 4 - Medianas dos grupos GC e GE das variáveis histológicas. Teste de mann-whitney 14 dias

\begin{tabular}{ccccc}
\hline & Controle Experimento & $\mathbf{U}$ & $\mathbf{p}$ \\
\hline $\begin{array}{c}\text { Proliferação } \\
\text { vascular }\end{array}$ & 1 & 1 & 1 & 0,2413 \\
$\begin{array}{c}\text { Mononucleares } \\
\text { Polimorfos }\end{array}$ & 1 & 2 & 1,5 & $* 0,0233$ \\
Proliferação & 2,5 & 3 & 2,75 & 0,4497 \\
fibroblástica & & & & \\
Fibras colágenas & 1 & 2 & 1,5 & $* 0,0025$ \\
Reepitelização & 2 & 2 & 2 & 0,7055 \\
\hline
\end{tabular}

Nota: A tabela mostra maior quantidade de mononucleares e de fibras colágenas no grupo experimento.

variáveis mononucleares e fibras colágenas. (Tabela 4)

No $21^{\circ}$ dia, ocorreu o mesmo que no 140 , mononucleares e fibras colágenas apresentaram resultados significativos ( $p$

TABELA 5 - Medianas dos grupos GC e GE das variáveis histológicas. Teste de Mann-Whitney- 21 dias.

\begin{tabular}{ccccc}
\hline & Controle Experimento & $\mathbf{U}$ & $\mathbf{p}$ \\
\hline $\begin{array}{c}\text { Proliferação } \\
\text { vascular }\end{array}$ & 1 & 1 & 1 & 0,257 \\
Mononucleares & 1 & 2 & 1,5 & $* 0,001$ \\
Polimorfos & 0 & 0 & 0 & 0,450 \\
Proliferação & 3 & 3 & 3 & 0,705 \\
fibroblástica & & & & \\
Fibras colágenas & 2 & 1 & 1,5 & $* 0,041$ \\
Reepitelização & 2 & 2 & 2 & 0,257 \\
\hline
\end{tabular}

Nota: A tabela mostra maior quantidade de mononucleares no Grupo experimeno enquanto o grupo controle possui mais fibras colágenas

$<0$ ’05\% ou $5 \%$ ), (Tabela 5 ).

Discussão

Foi escolhido o rato da linhagem Wistar como animal de experimentação, devido à facilidade de aquisição, manuseio, acomodação, resistência à agressão cirúrgica e a baixa mortalidade apresentada nos processos infecciosos ${ }^{9,10}$, e também foram todos machos e adultos, para evitar a interferência das variações hormonais do ciclo estral de fêmeas que poderiam interferir no mecanismo de reparação tecidual ${ }^{11,12}$.

Na revisão da literatura realizada não foram encontrados trabalhos clínicos ou experimentais que oferecessem fundamentos científicos para as ações farmacológicas do fruto do babaçu, mesmo sendo conhecido seu uso na medicina popular.
Foi escolhida solução aquosa de Orbignya phalerata e não a clorofórmica ou alcoólica para que a ação destes veículos não interferisse no sistema nervoso dos animais, alterando os resultados do processo de cicatrização.

A solução aquosa foi obtida do mesocarpo do babaçu, devido a que já existem citações de sua ação antiinflamatória em alguns estudos farmacológicos ${ }^{7,13}$.

A opção de usar $50 \mathrm{mg} / \mathrm{Kg}$ da solução fundamentou-se em trabalhos de pesquisa realizados anteriormente, onde também a via de administração intraperitoneal mostrou-se a mais utilizada.

Na literatura, encontram-se trabalhos em que os períodos de análise de cicatrização variaram de três a 21 dias 14,15. Aqui foram escolhidos os períodos de sete, 14 e 21 dias porque entre o $3^{\circ}$ e o $7^{\circ}$ as fases do processo não são muito diferentes, e no $21^{\circ}$ dia já existe cicatrização de ferida cirúrgica, podendo permitir comparação fiel.

\section{Avaliação macroscópica}

A retirada de fragmento de pele, induz a formação de solução de continuidade que é preenchida por fibrina, coágulo e exsudado inflamatório, formando a crosta que recobre a ferida ${ }^{10,14}$. No GE de sete dias e parte do de 14 dias, as crostas que se formaram foram mais intensas e as áreas estavam menores que o GC.

Calculou-se a área da ferida com a planimetria digital pelo software Auto Cad 14 por ser método atual e matemático após delimitação da periferia da lesão e demarcação dos pontos de maior eixo pelo método. Existem outros métodos para este fim, como o que utiliza o raio maior e menor e realiza a planigrafia, usando a fórmula $\mathrm{R} \times \mathrm{r} \times \pi=$ área, onde $\mathrm{R}$ é o raio maior, r é o raio menor e $\pi$ é igual a 3,1413 . Apesar deste método ter equivalência muito aproximada ao aqui usado não apresenta exatidão numérica igual e tão precisa como o Auto Cad 14.

Em relação à área da ferida, a análise de variância da planimetria mostrou que há efeito significativo de dias para o GE, resultando em valores de áreas menores que os do GC. Evidenciou-se, assim, que a substância atuou pontualmente no processo de cicatrização. Este fato foi verificado no $7^{\circ}$ dia quando foi comparado com o GC do mesmo período; entretanto, no GC de 14 dias houve efeito parcial e nenhum efeito aos 21 dias.

Os elementos inflamatórios presentes no sétimo $7^{\circ}$ dia e em alguns do $14^{\circ}$ dia comportaram-se diferentemente do GC. O que se pôde observar é que apenas no $7^{\circ}$ dia houve significativa diferença macroscópica.

\section{Avaliação microscópica}

A avaliação histológica dos fragmentos de pele retirados dos dois grupos mostrou diferenças qualitativas detectáveis na coloração pela Hematoxilina-Eosina e Tricrômio de Masson.

No início da fase inflamatória do processo de cicatrização há aumento da permeabilidade vascular, extravasamento de plasma, hemácias, plaquetas e leucócitos, destacando-se os neutrófilos, monócitos e macrófagos ${ }^{14,16}$. 
A diferença entre GC e GE foi mais visível, principalmente, na contagem de células mononucleares e fibras colágenas, havendo no $7^{\circ}$ dia diferença na proliferação fibroblástica e reepitelização.

$\mathrm{Na}$ fase da fibroplasia que ocorre após 48 horas da lesão, os fibroblastos se multiplicam e produzem o colágeno. Há também nesta fase, intensa proliferação endotelial, tendo como conseqüência a formação de tecido de granulação17.

No $7^{\circ}$ dia os mononucleares, polifibroblastos, fibras colágenas e reepitelização tiveram efeitos significativos positivos no GE. No $14^{\circ}$, somente apresentaram diferenças significativas os mononucleares e fibras colágenas no GE. No $21^{\circ}$ dia os mononucleares e fibras colágenas apresentaram resultados significativos favorecendo o GE, havendo aumento do primeiro e diminuição do segundo.

Existem trabalhos ${ }^{10,18}$ que mostram relação inversa entre fibroblastos e fibras colágenas no processo de reparação de feridas abertas sendo observado aumento crescente de fibras colágenas. Também verificou-se diminuição progressiva dos neutrófilos e capilares neoformados nos dias sete, 14 e 21 , concluindo que no $14^{\circ}$ dia ele existe em pequenas quantidades e é escasso no $21^{\circ}$ dia.

A hipóxia tecidual crônica mostrou-se como um dos mais potentes estimuladores da proliferação capilar na reparação tecidual e angiogênese. Ela forma brotos endoteliais em contigüidade com vasos sangüíneos, e suas células proliferam intensamente, formando cordões sólidos e sinuosos que se canalizam permitindo o fluxo sangüíneo através deles ${ }^{17}$.

O Brasil, possuidor de vasta e riquíssima flora com grande conteúdo de matéria prima, tem oferecido extenso campo para pesquisadores nacionais e internacionais em busca de substâncias com ação terapêutica nas várias doenças que acometem o planeta. Neste contexto, destaca-se a flora medicinal da Hiléia Amazônica do estado do Maranhão.

No presente trabalho, observou-se o efeito positivo da Orbignya phalerata no processo de cicatrização, coincidindo com outros estudos da literatura que demonstram também resultados positivos desta planta.

Contudo, algumas questões podem ser levantadas para melhor caracterizar a ação cicatrizante e também melhorar seu efeito, tais como: qual a melhor concentração do extrato?; qual a melhor dose?; qual a melhor posologia?; qual é do extrato(s) elemento(s) que é responsável pelo efeito cicatrizante?.

Assim, novos estudos com estes objetivos podem e devem ser estimulados para que, ao final, se possa dar credibilidade científica ao que este e outros trabalhos já sinalizam.

\section{Conclusão}

Observou-se ação estimulante da cicatrização em ferimentos de pele de ratos com o uso do extrato aquoso da Orbignya phalerata, tanto na avaliação macroscópica como na microscópica.

\section{Referências}

1. Bibby BA, Collins BJ, Ayliffe GAJ. A Mathematical Model for Assessing the Risk of Post-Operative wound Infecttion. J Infect. 1986; 8:31-8.

2. Chmell MJ, Schwartz H S. Analysis of variables affecting wound healing after musculoskeletal sarcoma resections. J Surg Oncol. 1996; 61:185-9.

3. Pires FOC. O babaçu no Maranhão. Considerações sobre a espécie encontrada e sua importância. São Luis: Fundação IBGE. Centro brasileiro de Estatística Agropecuárias 1974.

4. Baxter AG, Cooke A. Complement lytic activity has no role in the pathogenesis of autoimmune diabetes in NOD mice. Diabetes. 1993; 42: 1574-8.

5. Malawista SE, Montgomery RR, van Blaricom G. Evidence for reactive nitrogen intermediates in killing of sthaphilococci by human neutrophil cytoplasts. A new microbicidal pathway for polymorphonuclear leukocytes. J Clin Invest. 1992; 90:631- 6.

6. Deenen GJ, Kroese FGM. "Kinetics of peritoneal B-1a cells (CD5 B cells) in young adult mice". Eur J Immunol. 1993; 23:12-6.

7. Maia MBS. Estudo de atividade antiinflamatória e outros efeitos farmacológicos relacionados de Orbignya phalerata Mart. [Dissertação-Mestrado]. Fortaleza: Universidade Federal do Ceará, Departamento de Fisiologia e Farmacologia ; 1987.

8. Chvapil M, Koopmann CF, Scar formation: physiology and pathological states. Otolaryngol Clin North Am. 1984;17:265-72.

9. Marchini FB. Estudo Morfológico e morfométrico da cicatrização de feridas cutâneas abertas em ratos albinos com e sem tratamento com óleo de rosa mosqueta. [Tese-Mestrado]. São Paulo: Escola Paulista de Medicina; 1994.

10. Simões MJ, Uzunian A, Mora AO, Sasso WS. Aspectos ultra-estruturais do processo de reparação da pele de ratos albinos. Rev Paul Med. 1985; 103:123-6.

11. Harris AK, Stopak D, Wild P. Fibroblast traction as a mechanism for collagen morphogenesis. Nature. 1981; 290:249-51.

12. Belivacqua RG, Modolin MLA, Almeida CG, Chapchap P. Cicatrização. In: Goldenberg S, Bevilacqua RG, editores. Manual de Cirurgia. $2^{\mathrm{a}}$ ed. São Paulo: EPU/ Springer; 1981. p. 99-116.

13. Lawrence WT, Norton JA, Sporn MB, Gorschboth $\mathrm{C}$, Grotendorst GR. The reversal of na ${ }^{a}$ Adriamycin induced healing impairment with chemoattractants and growth factors. Ann Surg. 1986; 203:142-7.

14. Simões MJ, Cabral ACV, Boyaciyan K, Kulay Jr. L, Sasso WS. Aspectos ultra-estruturais dos fibroblastos e dos macrófagos durante o processo de reparação da pele de ratos. Rev Paul Med. 1986; 104:132-5.

15. Modolin M, Bevilacqua RG. Cicatrização das feridas: síntese das aquisições recentes. Rev Bras Clin ter. 1985; 


\section{4:208-13.}

16. Alvares S. Contribuição para o estudo histométrico e histoquímico do processo de reparação de lesão obtidas experimentalmente na pele de ratos albinos. [Tese - Doutorado]. São Paulo: Faculdade de Odontologia da Universidade de São Paulo;1972

17. Sanchez-Neto R, Barone B, Teves DC, Simões MJ, Novo NF, Juliano Y. Aspectos morfológicos e morfométricos da reparação tecidual de feridas cutâneas de ratos com e sem tratamento com solução de papaína a 2\%. Acta Cir
Bras. 1993; 8:18-23.

18. France QI. Manual de botânica econômica do Maranhão. São Luís: Universitária da Universidade Federal do Maranhão.

\section{Correspondência:}

Conflito de interesses: nenhum Fonte de financiamento: Capes

Recebimento: 07/02/2005

Revisão: 02/06/2005

Aprovação: 11/06/2006

\section{Como citar este artigo:}

Martins NLP, Malafaia O, Ribas-Filha JM, Heibel M, Baldez RN, Vasconcelos PRL, Moreira H, Mazza M, NassifPAN. Análise comparativa da cicatrização da pele com o uso intraperitoneal de extrato aquoso de Orbignya phalerata (babaçu). Estudo controlado em ratos. Acta Cir Bras. [periódico na internet] 2006;21 Supl 3:66-75. Disponível em URL: http://www.scielo.br/acb

*Figuras coloridas disponíveis em www.scielo.br/acb 